\title{
Desempenho de cultivares elites de mandioca industrial em área de cerrado do Mato Grosso do Sul
}

\section{Performance of elite cultivars of industrial cassava in savannah area of Mato Grosso do Sul State, Brazil}

\author{
Auro Akio Otsubo ${ }^{1 *}$; Osmar Rodrigues Brito ${ }^{2}$; Fábio Martins Mercante ${ }^{1}$; \\ Victor Hugo Nakase Otsubo²; Marcos Aparecido Gonçalves²; Tiago Santos Telles ${ }^{2}$
}

\section{Resumo}

O trabalho foi conduzido com o objetivo de avaliar o desempenho de cultivares elites de mandioca, tipo industrial, em São Gabriel do Oeste, MS, em área típica de vegetação de cerrado. As cultivares IAC 12, IAC 13, IAC 14, IAC 15, IAC 576, Fécula Branca, Espeto e Fibra foram avaliadas quanto a altura de planta, massa fresca de parte aérea, massa fresca de cepa, número de raiz, produção de raiz, teor de amido e índice de colheita. O delineamento experimental utilizado foi o de blocos casualizados com oito tratamentos (cultivares) e cinco repetições. O sistema de plantio utilizado foi o de fileiras simples, com espaçamento de $0,90 \mathrm{~m} \times 0,70 \mathrm{~m}$. A colheita foi realizada após 16 meses do plantio. A cultivar IAC 14 foi a que apresentou maior altura de planta, destacando-se também junto com a IAC 15 na produção de massa fresca da parte aérea. Em relação à produção de raiz, sobressaíram as cultivares IAC 12, IAC 14, IAC 13, IAC 15 e Fibra que não diferiram entre si. Os maiores teores de amido, em ordem decrescente, foram observados nas cultivares IAC 13, IAC 12, IAC 14, Fibra e IAC 15.

Palavras-chave: Manihot esculenta, clones, matéria seca, fécula

\begin{abstract}
The work was carried out to evaluate the performance of industrial type of the elite cassava cultivars, in Sao Gabriel do Oeste, MS, Brazil, in typical area of savannah vegetation. The IAC 12, IAC 13, IAC 14, IAC 15, IAC 576, Fécula Branca, Espeto and Fibra cultivars were evaluated on plant height, fresh mass of shoots, fresh mass of planting stub, number of root, root production, starch content and harvest index. The experimental design was a randomized block with eight treatments (cultivars) and five replications. The crop was installed using spacing of $0,90 \mathrm{~m} \times 0,70 \mathrm{~m}$ between lines. The harvest was done six months after the planting date. The cultivar IAC 14 presented the highest plant height. IAC14 and IAC 15 presented the highest fresh matter production of the shoot. The cultivars IAC 12, IAC 13, IAC 14, IAC 15 and Fibra presented the highest yields. The cultivars IAC 576 and Espeto had the lowest root production. The highest contents of starch, in decreasing order, were observed to IAC 13, IAC 12, IAC 14, Fiber and IAC 15.
\end{abstract}

Key words: Manihot esculenta, clones, dry matter, starch

\footnotetext{
Pesquisador da Embrapa Agropecuária Oeste, CP: 661, CEP: 79804-970. Dourados, MS. E-mail: auro.ao@hotmail.com

2 Universidade Estadual de Londrina, CEP: 86051-990, Londrina, PR

Autor para correspondência
} 


\section{Introdução}

O cultivo da mandioca (Manihot esculenta Crantz) no estado do Mato Grosso do Sul concentrase na região sul, que apresenta características edafoclimáticas e fundiárias (pequenas propriedades) adequadas para o seu cultivo, além disso, é onde se encontra instalado o parque industrial processador desta tuberosa. Junto com os estados do Paraná e São Paulo, constituem-se na maior região produtora de amido de mandioca do Brasil. Esse cenário tem contribuído nos últimos anos para o crescimento da área plantada e da produção de mandioca (ANUÁRIO DA AGRICULTURA BRASILEIRA, 2007). Entretanto, esta região vem-se transformando na nova fronteira de expansão da cultura de cana de açúcar com implantação de algumas destilarias de álcool. Além disso, na região é comum o arrendamento de terras para o plantio de milho e soja, dificultando o estabelecimento de novas áreas com o cultivo de mandioca em razão do menor ciclo, garantia de mercado para os produtos das referidas culturas e principalmente pela valorização da terra nua.

A busca por novas áreas para o estabelecimento de cultivos, voltados para o abastecimento do parque industrial de processamento da mandioca, se faz cada vez mais urgente para transformar esta cultura em estratégia econômica de revitalização de regiões mais fracas em termos de ocupação de mão de obra e geração de recursos. Nesse sentido, o cerrado brasileiro pode ser uma alternativa interessante, pois além de grandes extensões (GARBA, 1994), as terras disponíveis ainda são de baixo valor comercial. A região norte do Estado do Mato Grosso do Sul pode se constituir em opção viável, entretanto, ainda não se dispõe de informações seguras sobre o desempenho produtivo da cultura da mandioca, principalmente para cultivares de uso industrial.

Apesar de se adaptar aos mais diferentes agroecossistemas, a cultura da mandioca apresenta alta interação genótipo $\mathrm{x}$ ambiente, ou seja, as cultivares apresentam adaptação específica às condições edafoclimáticas de uma determinada região, diminuindo as possibilidades de um mesmo material apresentar desempenho produtivo adequado em uma ampla região agrícola (FUKUDA et al., 2006). Isso irá demandar um amplo trabalho de pesquisa de melhoramento vegetal e seleção de materiais de alto desempenho produtivo.

A introdução de cultivares, em uma nova área deve ser feita com critério para evitar riscos de transferência de inóculos de patógenos e novas pragas. No caso da cultura da mandioca essa questão reveste-se de grande importância em razão da multiplicação da cultura se dar por meio de propagação vegetativa, baseada na utilização de fragmentos de caule (tolete) de uma planta matriz. Nesta situação como destaca Fukuda (1993), a disseminação de pragas e doenças pode comprometer a expansão da cultura ou o estabelecimento de novos pólos de exploração com a mandioca. Nesse sentido, ainda de acordo com Fukuda, Romeiro e Fukuda (1984) embora a mandioca seja considerada como planta rústica, a pressão de agentes patogênicos, como Xanthomonas campestris pv. manihotis, pode causar severos danos à cultura podendo reduzir a produtividade em mais de $50 \%$, dependendo das condições ambientais locais e do grau de resistência do material. Ressalta-se ainda que a bacteriose é a principal doença que limita a expansão da cultura da mandioca na região centro sul do Brasil.

Sagrilo, Otsubo e Silva (2007) destacam que a introdução de genótipos e posterior avaliação, constitui-se no mais simples, barato e mais importante método de melhoramento atualmente empregado na cultura da mandioca. O lançamento de uma nova cultivar de mandioca demanda vários anos de estudos, período que pode ser reduzido mediante introdução e seleção de materiais de reconhecida qualidade superior, já testados ou utilizados comercialmente em outras regiões. Estes materiais, normalmente denominados de cultivares elites, são aqueles que apresentam as características desejadas pelo setor industrial, principal consumidor da mandioca produzida no Brasil. 
Segundo Ceballos et al (2002), a identificação de cultivares ou variedades de qualidade superior, só é conseguida mediante exaustivos trabalhos de pesquisa em áreas localizadas em regiões que apresente condições edafoclimáticas semelhantes àquelas desejadas. Esse sistema de estudo e avaliação de novos materiais de mandioca tem sido freqüentemente utilizado em várias regiões do Brasil, como indicam os trabalhos realizados por Vidigal Filho et al. (2000) para a região noroeste do Paraná, Mendonça, Moura e Cunha (2003) para o estado do Acre, Fialho, Fukuda e Vieira (2005) para o Distrito Federal, Sagrilo, Otsubo e Silva (2007) para a região do Vale do Ivinhema em Mato Grosso do Sul e Otsubo et al. (2007) para a região sul do Mato Grosso do Sul.

Diante da situação exposta anteriormente, realizou-se o presente estudo com o objetivo de estudar e avaliar o comportamento de cultivares elite de mandioca para fins industriais em uma área de cerrado da região norte do Mato Grosso do Sul.

\section{Material e métodos}

O experimento foi conduzido no período de julho/2006 a novembro/2007, em área com vegetação típica de cerrado, no município de São Gabriel do Oeste, MS (latitude: 19²3'S; longitude: $\left.54^{\circ} 23^{\prime} \mathrm{W}\right)$. O solo da área foi classificado com de ocorrência de Latossolo Vermelho escuro e apresentaram as seguintes características químicas: $\mathrm{pH}\left(\mathrm{CaCl}_{2}\right) 4,56 ; 5,47 \mathrm{mg} \mathrm{dm}^{-3}$ de $\mathrm{P} ; 27,73 \mathrm{~g} \mathrm{dm}^{-3} \mathrm{de}$ MO; $0,09 \mathrm{cmol}_{\mathrm{c}} \mathrm{dm}^{-3}$ de K; $1,27 \mathrm{cmol}_{\mathrm{c}} \mathrm{dm}^{-3} \mathrm{de} \mathrm{Ca}$; $0,89 \mathrm{cmol}_{\mathrm{c}} \mathrm{dm}^{-3}$ de $\mathrm{Mg}$ e 4,43 $\mathrm{cmol}_{\mathrm{c}} \mathrm{dm}^{-3} \mathrm{de} \mathrm{H}+\mathrm{Al}$. Foram testadas as seguintes cultivares de mandioca: IAC 12, IAC 13, IAC 14, IAC 15, IAC 576, Espeto, Fécula Branca e Fibra. As ramas utilizadas para preparação das manivas de plantio foram obtidas de culturas de mandioca de alta qualidade sanitária do Campo Experimental de Pindorama, do Instituto Agronômico de Campinas. Na Tabela 1 encontramse algumas características botânico-agronômica das cultivares IAC 12, IAC 13, IAC 14, Espeto, Fécula Branca e Fibra Vidigal Filho et al. (2000) e IAC 15 e IAC 576. O delineamento experimental utilizado foi o de blocos casualizados com oito tratamentos (cultivares de mandioca) e cinco repetições.

Tabela 1. Caracterização botânico-agronômica da parte aérea de oito cultivares de mandioca, São Gabriel do Oeste, MS, 2007.

\section{Cultivares}

\begin{tabular}{|c|c|c|c|c|c|c|c|c|}
\hline Características & IAC 12 & IAC 13 & IAC 14 & IAC 15 & IAC 576 & $\begin{array}{l}\text { Fécula } \\
\text { Branca }\end{array}$ & Espeto & Fibra \\
\hline Lóbulo da folha & $\begin{array}{l}\text { Obovado } \\
\text { liso }\end{array}$ & $\begin{array}{l}\text { Obovado } \\
\text { liso }\end{array}$ & $\begin{array}{l}\text { Obovado } \\
\text { liso }\end{array}$ & $\begin{array}{l}\text { Obovado } \\
\text { liso }\end{array}$ & $\begin{array}{l}\text { Obovado } \\
\text { liso }\end{array}$ & $\begin{array}{l}\text { Obovado } \\
\text { liso }\end{array}$ & $\begin{array}{l}\text { Linear } \\
\text { sinuoso }\end{array}$ & $\begin{array}{l}\text { Linear pouco } \\
\text { sinuoso }\end{array}$ \\
\hline $\begin{array}{l}\text { Coloração do } \\
\text { pecíolo }\end{array}$ & Vinho & $\begin{array}{l}\text { Verde } \\
\text { arroxeada }\end{array}$ & Vinho & $\begin{array}{l}\text { Verde } \\
\text { arroxeada }\end{array}$ & Verde & Vermelha & Vinho clara & Vermelha \\
\hline $\begin{array}{l}\text { Coloração da } \\
\text { brotação nova }\end{array}$ & $\begin{array}{l}\text { Verde } \\
\text { arroxeada }\end{array}$ & $\begin{array}{l}\text { Verde } \\
\text { arroxeada }\end{array}$ & $\begin{array}{l}\text { Verde } \\
\text { arroxeada }\end{array}$ & $\begin{array}{l}\text { Verde } \\
\text { arroxeada }\end{array}$ & Verde & $\begin{array}{l}\text { Verde } \\
\text { arroxeada }\end{array}$ & $\begin{array}{l}\text { Verde } \\
\text { arroxeada }\end{array}$ & Verde \\
\hline Ramificação & Tricotômica & Tricotômica & Tricotômica & Tricotômica & Tricotômica & Tricotômica & Tricotômica & Tricotômica \\
\hline Florescimento & Floresce & Floresce & Floresce & Floresce & Floresce & Floresce & Floresce & Floresce \\
\hline $\begin{array}{l}\text { Coloração da rama } \\
\text { madura }\end{array}$ & $\begin{array}{l}\text { Marrom } \\
\text { escura }\end{array}$ & $\begin{array}{l}\text { Cinza } \\
\text { prateada }\end{array}$ & $\begin{array}{l}\text { Cinza } \\
\text { prateada }\end{array}$ & $\begin{array}{l}\text { Cinza } \\
\text { prateada }\end{array}$ & $\begin{array}{l}\text { Cinza } \\
\text { prateada }\end{array}$ & $\begin{array}{l}\text { Cinza } \\
\text { prateada }\end{array}$ & $\begin{array}{l}\text { Cinza } \\
\text { prateada }\end{array}$ & $\begin{array}{l}\text { Cinza } \\
\text { prateada }\end{array}$ \\
\hline $\begin{array}{l}\text { Susceptibilidade à } \\
\text { bacteriose }\end{array}$ & Mediana & Mediana & Baixa & Mediana & Mediana & Baixa & Alta & Alta \\
\hline
\end{tabular}


Para implantação do experimento a área foi preparada de forma convencional com uma aração e duas gradagens. $\mathrm{O}$ espaçamento utilizado foi o de $0,90 \mathrm{~m}$ x 0,70 m utilizando o sistema de fileiras simples. A adubação de plantio foi realizada através da aplicação de $350 \mathrm{~kg} \mathrm{ha}^{-1}$ do formulado NPK + Zn (04-20-20), no sulco, conforme recomendações de Lorenzi e Dias (1993). Para o plantio utilizouse manivas com $20 \mathrm{~cm}$ de comprimento, que foram dispostas horizontalmente no fundo do sulco de plantio a uma profundidade aproximada de $10 \mathrm{~cm}$.

As parcelas experimentais foram constituídas por um conjunto de 4 linhas com 10 plantas cada. A área útil foi representada pelas duas linhas centrais, desprezando duas plantas de cada extremidade. A colheita foi realizada aos 16 meses do plantio. As precipitações ocorridas durante o período experimental se encontram na figura 1 .

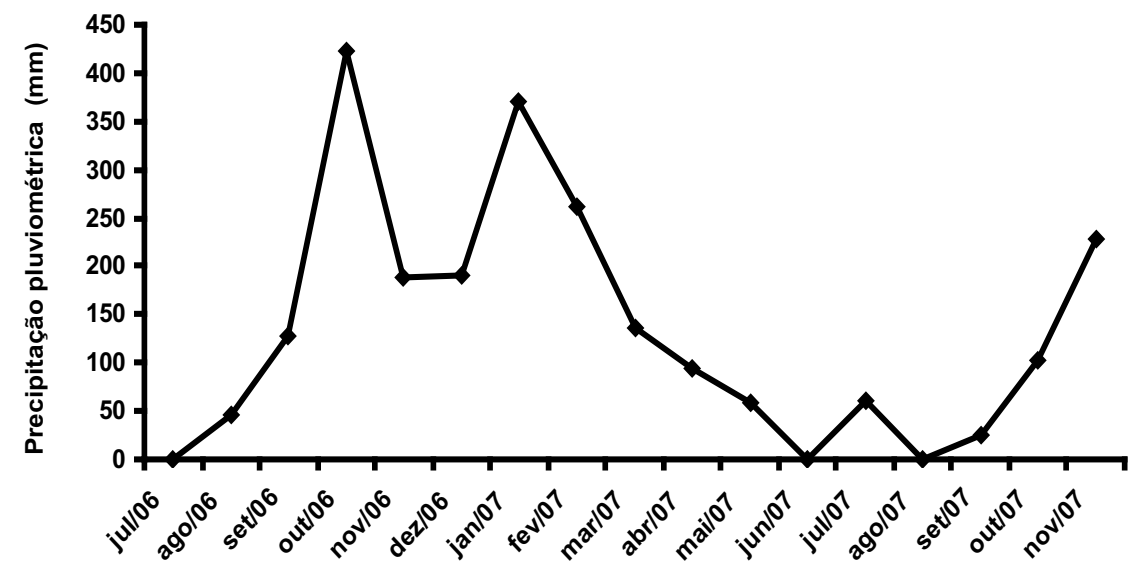

Figura 1. Totais mensais da precipitação pluviométrica ocorrida entre julho/2006 a novembro/2007, durante o período experimental, em São Gabriel do Oeste-MS. (Fonte: Prefeitura Municipal de São Gabriel do Oeste).

Foram avaliadas as seguintes variáveis: a) Altura de plantas (AP): medida a partir do nível do solo até o broto terminal de cada planta, por ocasião da colheita; b) Massa fresca da parte aérea (MFPA); c) Massa fresca de cepa (MFC); d) Massa de raízes (MR); e) Número de raízes (NR); f) Teor de amido (TA), mediante emprego da metodologia da balança hidrostática descrita em Conceição (1979) e g) Índice de colheita (IC), calculado como a relação entre massa de raízes tuberosas e a massa total das plantas (massa de raiz + massa da parte aérea + massa de cepa).

Os dados obtidos foram submetidos à análise de variância e as médias comparadas pelo teste de Tukey a $5 \%$.

\section{Resultados e discussão}

Considerando a altura de plantas, verificou-se que a cultivar IAC 14 foi a que apresentou a maior altura média, diferindo significativamente das demais (Tabela 2). Os menores valores para altura de plantas foram observados nas cultivares Fécula Branca, Espeto e Fibra. Resultados semelhantes, para a cultivar IAC 14, foram observados por Sagrilo, Otsubo e Silva (2007); Otsubo et al. (2007) e Zatarin et al. (2005) em diferentes regiões do Mato Grosso do Sul e por Vidigal Filho et al. (2000) na região noroeste do estado do Paraná. Os valores para altura de plantas estão dentro da média para a cultura (1,0 a 5,0m), mas de acordo com Montaldo (1972), a seleção de cultivares de porte mais baixo é importante principalmente para áreas de solos férteis de regiões sujeitas a ventos fortes, pois o crescimento excessivo da planta pode favorecer o acamamento como observado por Acosta-Espinoza (1984). Nesse trabalho o tombamento de plantas foi observado apenas para o cultivar IAC 14, em torno de $43 \%$ das plantas. 
Tabela 2. Valores médios para altura de plantas (AP), massa fresca da parte aérea (MPA) e massa fresca de cepa (MC) para diferentes cultivares de mandioca. São Gabriel do Oeste, MS. 2007.

\begin{tabular}{cccc}
\hline Cultivares & AP $(\mathbf{m})$ & MPA $\left(\mathbf{k g ~ h a}^{-1}\right)$ & MCEPA $\left(\mathbf{k g ~ h a} \mathbf{~}^{-1}\right)$ \\
\hline IAC 12 & $1,94 \mathrm{de}$ & $28.654 \mathrm{bc}$ & $10.299 \mathrm{~b}$ \\
IAC 13 & $2,02 \mathrm{~cd}$ & $29.803 \mathrm{~b}$ & $10.483 \mathrm{ab}$ \\
IAC 14 & $2,96 \mathrm{a}$ & $39.073 \mathrm{a}$ & $9.524 \mathrm{~b}$ \\
IAC 15 & $2,24 \mathrm{~b}$ & $40.057 \mathrm{a}$ & $12.641 \mathrm{a}$ \\
IAC 576 & $2,18 \mathrm{bc}$ & $28.133 \mathrm{bc}$ & $9.778 \mathrm{~b}$ \\
Espeto & $1,68 \mathrm{f}$ & $20.730 \mathrm{~cd}$ & $6.038 \mathrm{c}$ \\
Fécula Branca & $1,65 \mathrm{f}$ & $12.676 \mathrm{~d}$ & $6.571 \mathrm{c}$ \\
Fibra & $1,74 \mathrm{ef}$ & $12.527 \mathrm{~d}$ & $8.787 \mathrm{~b}$ \\
\hline F & $92,64^{* *}$ & $30,49^{* *}$ & $20,67^{* *}$ \\
\hline C.V. $(\%)$ & 4,85 & 16,15 & 11,38 \\
\hline
\end{tabular}

Médias seguidas da mesma letra nas colunas não diferem entre si pelo teste de Tukey a 5\%.

Quanto a produção de fitomassa da parte aérea, destacaram-se as cultivares IAC 15 e a IAC 14 que apresentaram produções semelhantes entre si, mas significativamente superior às demais. As menores produções foram obtidas com as cultivares Fibra, Fécula Branca e Espeto (Tabela 2). Resultados semelhantes foram observados por Sagrilo, Otsubo e Silva (2007) em três diferentes ambientes. Por outro lado, os valores observados na IAC 14 superaram aqueles observados por Sagrilo et al. (2002). Segundo esses mesmos autores, a produção de fitomassa da parte aérea é influenciada pelas condições climáticas, uma vez que altas temperaturas aliadas à precipitações intensas, favorece o crescimento das hastes e a produção de folhas. Estas condições ambientais ocorrem com freqüência na região onde foi implantado o experimento e pode ter favorecido os cultivares mais adaptados (Figura 1). A produção de fitomassa da parte aérea é uma característica importante para a cultura da mandioca, pois as ramas são utilizadas como material propagativo para instalação de novos campos de produção. Por outro lado, tanto as ramas com as folhas das plantas de mandioca podem ser utilizadas na produção de rações de excelente qualidade protéica, utilizada na alimentação de diferentes animais (MATTOS, 2006).
A massa de cepas foi maior nas cultivares IAC 15 e a IAC 13 que diferiram dos demais materiais testados mas não entre si (Tabela 2). A produção de cepas resulta no consumo de fotoassimilados e de energia e por último interfere na produtividade da cultura e reduzindo o índice de colheita. Entretanto as cepas produzidas podem ser destinadas para queima e geração de calor para aquecimento de fornos de torra da farinha ou caldeiras. Se comercializado em separado pode se tornar uma fonte extra de recursos para os produtores de mandioca.

Quanto ao número de raízes produzidas, destacaram-se as cultivares IAC 15, IAC 14, IAC 12 e IAC 13 (Tabela 3). Os números observados são superiores àqueles obtidos por Otsubo et al. (2007), em um solo de textura argilosa. Os menores números de raízes foram observados para as cultivares IAC 576, Fibra, Fécula Branca e Espeto. A raiz é o produto da cultura de mandioca de maior valor econômico, pois dela se extrai o amido, principal produto industrial. Segundo Carvalho e Fukuda (2006) uma planta de mandioca pode produzir de uma até dez raízes. 
Tabela 3. Valores médios para número de raízes (NR), produtividade (PR), teor de amido (TA) e índice de colheita (IC) para diferentes cultivares de mandioca. São Gabriel do Oeste, MS. 2007.

\begin{tabular}{ccccc}
\hline Cultivares & NR $\left(\mathbf{n}^{\mathbf{0}} \mathbf{h a}^{-\mathbf{1}}\right)$ & PR $\left(\mathbf{k g ~ h a}^{-\mathbf{1}}\right)$ & TA (\%) & IC (\%) \\
\hline IAC 12 & $154.602 \mathrm{ab}$ & $54.520 \mathrm{a}$ & $25,79 \mathrm{ab}$ & $58,57 \mathrm{~b}$ \\
IAC 13 & $143.808 \mathrm{abc}$ & $48.019 \mathrm{ab}$ & $26,61 \mathrm{a}$ & $54,38 \mathrm{bc}$ \\
IAC 14 & $158.729 \mathrm{a}$ & $48.800 \mathrm{ab}$ & $25,33 \mathrm{abc}$ & $50,05 \mathrm{~cd}$ \\
IAC 15 & $171.109 \mathrm{a}$ & $46.968 \mathrm{abc}$ & $22,85 \mathrm{abc}$ & $47,08 \mathrm{~d}$ \\
IAC 576 & $112.697 \mathrm{c}$ & $36.184 \mathrm{c}$ & $20,68 \mathrm{c}$ & $48,88 \mathrm{~cd}$ \\
Espeto & $119.364 \mathrm{bc}$ & $37.542 \mathrm{bc}$ & $20,73 \mathrm{c}$ & $58,39 \mathrm{~b}$ \\
Fécula Branca & $116.824 \mathrm{c}$ & $47.371 \mathrm{abc}$ & $21,58 \mathrm{bc}$ & $71,04 \mathrm{a}$ \\
Fibra & $117.777 \mathrm{c}$ & $46.939 \mathrm{abc}$ & $23,18 \mathrm{abc}$ & $68,73 \mathrm{a}$ \\
\hline F & $4,61^{* *}$ & $5,85^{* *}$ & $4,60^{* *}$ & $48,04^{* *}$ \\
\hline C.V. (\%) & 12,59 & 12,21 & 10,39 & 5,04 \\
\hline
\end{tabular}

Médias seguidas de mesma letra nas colunas não diferem entre si, pelo teste de Tukey a 5\%.

Quando se considera a produtividade da cultura em temos de massa de raízes, observou-se que as cultivares que mais se destacaram foram a IAC 12, IAC 14, IAC 13, IAC 15 e Fibra não havendo diferenças significativas entre elas. A menor produtividade de raízes foi obtida com a cultivar IAC 576 (Tabela 3). Vários trabalhos corroboram os resultados obtidos neste estudo, destacando-se os de Sagrilo, Otsubo e Silva (2007), Otsubo et al. (2007) e Vidigal Filho et al. (2000), exceto para a cultivar IAC 13, que apresentou a menor produtividade. A qualidade excepcional e a sanidade do material de propagação utilizado deve ter contribuído para tal fato. Além disso, a área utilizada para instalação dos experimentos estava praticamente livre de propágulos de patógenos específicos da cultura da mandioca, uma vez que a ocorrência de pragas e doenças na cultura foi considerada baixa. Devese destacar que mesmo as menores produtividades observadas neste trabalho (IAC $576=36.184 \mathrm{~kg} \mathrm{ha}^{-1}$ e Espeto $\left.=37.542 \mathrm{~kg} \mathrm{ha}^{-1}\right)$, ficaram acima da média estadual que é de $17.431 \mathrm{~kg} \mathrm{ha}^{-1}$ (AGRIANUAL, 2007). Outro fator que pode ter contribuído para obtenção dos altos valores de produtividade observados neste estudo foi a idade das plantas (16 meses) na época de colheita. De acordo com Sagrilo et al. (2002), os maiores incrementos na biomassa de raízes na cultura da mandioca ocorrem ente o $15^{\circ}$ e o $19^{\circ}$ meses de idade das plantas.
O teor de amido das raízes colhidas variou entre as cultivares e os maiores valores para esta variável foram observados para as cultivares IAC 13, IAC 12, IAC 14, Fibra e IAC 15. Os menores valores foram verificados nas cultivares IAC 576 e Espeto (Tabela 3). Trabalhos como os de Sagrilo, Otsubo e Silva (2007) e Vidigal Filho et al. (2000), confirmam o potencial genético de produção de amido da cultivar IAC 13, como observado neste estudo. Já os trabalhos de Pereira Neto, Otsubo e Martins (2001) e de Kruker, Otsubo e Martins (2001) confirmam o potencial das cultivares IAC 13 e IAC 14. Porém, diferiram quanto ao potencial da cultivar IAC 15, que neste estudo apresentou os menores teores de amido nas raízes. Entretanto, esse menor potencial observado para a cultivar IAC15 está de acordo com os resultados apresentados por Sagrilo, Otsubo e Silva (2007). Deve-se destacar ainda que o teor de amido nas raízes é uma característica muito importante, pois é utilizada pela indústria como critério de avaliação da qualidade e pagamento pela mandioca adquirida dos produtores associados.

Apesar de apresentarem as menores produtividades e teores de amido, as cultivares Fécula Branca e Fibra apresentaram os maiores valores para índice de colheita, 71,04\% e 68,73\%, respectivamente (Tabela 3). Entretanto como alerta Cardoso Júnior et al. (2005), estes valores podem 
ser alcançados devido ao menor porte e produção de massa fresca da parte aérea, como observados neste estudo e aqueles executados por Otsubo et al., 2008.

\section{Conclusão}

Por apresentarem altas produtividades e teores de amido as cultivares IAC 12, IAC 13, IAC 14, IAC 15, Fécula Branca e Fibra, possuem potencial para o cultivo na região norte do Mato Grosso do Sul.

\section{Agradecimentos}

Os autores agradecem a prefeitura municipal de São Gabriel do Oeste pela cedência da área experimental e apoio logístico na condução dos trabalhos.

\section{Referências}

ACOSTA-ESPINOZA, J. A. Variabilidade e associações genéticas entre caracteres de mandioca (Manihot esculenta Crantz) combinando policruzamentos e propagação vegetativa. 1984. Tese (Doutorado em Agronomia) - Escola Superior de Agricultura Luiz de Queiroz, Universidade de São Paulo, Piracicaba, 1984.

ANUÁRIO DA AGRICULTURA BRASILEIRA AGRIANUAL. Agrianual 2007. São Paulo: Instituto FNP, 2007. p. 373-377.

CARDOSO JÚNIOR, N. S.; VIANA, A. E. S.; MATSUMOTO, S. N.; SEDIYAMA, T.; CARVALHO, F. M. Efeito do nitrogênio em características agronômicas da mandioca. Bragantia, Campinas, v. 64, n. 4, p. 651659, 2005.

CARVALHO, P. C. L.; FUKUDA, W. M. G. Estrutura da planta e morfologia. In: SOUZA, L. S.; FARIAS, A. R. N.; MATTOS, P. L. P.; FUKUDA, W. M. G. (Ed.). Aspectos socioeconômicos e agronômicos da mandioca. Cruz das Almas: Embrapa Mandioca e Fruticultura, 2006. p. 126-137.

CEBALlOS, H.; MORANTE, N.; CALLE, F.; LENIS, J. I.; JARAMILLO, G.; PEREZ, J. C. Mejoramiento genético de la yuca. In: OSPINA, B.; CEBALLOS, $\mathrm{H}$. (Compilación y dirección). La yuca en tercer milenio: sistemas modernos de producción, procesamiento, utilización y comercialización. Cali: CIAT/CLAYUCA, 2002. p. 295-325.

CONCEIÇÃO, A. J. A mandioca. Cruz das Almas: UFBA/EMBRAPA/BN/BRASCAN NORDESTE, 1979. $382 \mathrm{p}$.

FIALHO, J. F.; FUKUDA, W. M. G.; VIEIRA, E. A. Avaliação de variedades de mandioca no Distrito Federal. In: CONGRESSO BRASILEIRO DE MANDIOCA, 11., 2005, Campo Grande. Anais... Campo Grande: Embrapa Agropecuária Oeste, 2005.

FUKUDA, C. Doenças de mandioca. In: Instruções práticas para o cultivo da mandioca. $\overline{\text { Cruz das }}$ Almas: EMBRAPA, 1993. p. 53-56.

FUKUDA, C.; ROMEIRO, R. S.; FUKUDA, W. M. G. Avaliação da resistência de cultivares de mandioca a Xanthomonas campestris pv. manihotis. Revista Brasileira de Mandioca, Cruz das Almas, v. 3, n. 1, p. 7-12, 1984.

FUKUDA, W. M. G.; FUKUDA, C.; DIAS, M. C.; XAVIER, J. J. B. N.; FIALHO, J. F. Variedades. In: SOUZA, L. S.; FARIAS, A. R. N.; MATTOS, P. L. P.; FUKUDA, W. M. G. (Ed.). Aspectos socioeconômicos e agronômicos da mandioca. Cruz das Almas: Embrapa Mandioca e Fruticultura, 2006. p. 433-454.

GARBA. E.C. Atlas do meio ambiente do Brasil. Brasília: EMBRAPA-SPI, 1994.

KRUKER, F.; OTSUBO, A. A.; MARTINS, C. S. Avaliação de cultivares de mandioca industrial em Dourados, MS. In: CONGRESSO NACIONAL DE INICIAÇÃO CIENTÍFICA, 1., 2001, São Paulo. Anais... São Paulo: SEMESP, 2001. v. 1, p. 222.

LORENZI, J. O.; DIAS, C. A. C. Cultura da mandioca. Campinas: CATI, 1993. 41 p. (Boletim Técnico, n· 211).

MATTOS, P. L. P. Implantação da cultura. In: SOUZA, L. S.; FARIAS, A. R. N.; MATTOS, P. L. P.; FUKUDA, W. M. G. (Ed.). Aspectos socioeconômicos e agronômicos da mandioca. Cruz das Almas: Embrapa Mandioca e Fruticultura, 2006. p. 492-517.

MENDONÇA, H. A.; MOURA, G. M.; CUNHA, E. T. Avaliação de genótipos de mandioca em diferentes épocas de colheita no Estado do Acre. Pesquisa Agropecuária Brasileira, Brasília, v. 38, n. 6, p. 761-769, jun., 2003.

MONTALDO, A. Cultivo de raices y tubérculos tropicales. Lima: IICA, 1972. 248 p.

OTSUBO, A. A.; MERCANTE, F. M.; SILVA, R. F.; BORGES, C. D. Sistemas de preparo do solo, plantas de cobertura e produtividade da cultura da mandioca. Pesquisa Agropecuária Brasileira, Rio de Janeiro, v. 43, n. 3, p. 327-332, mar. 2008. 
OTSUBO, A. A.; SAGRILO, E.; LORENZI, J. O.; GALHARINI, L. G. S.; OTSUBO, I. M. N.; MATOS, J. S.; UTIDA, D.; FUJINAKA, J. Avaliação de clones de mandioca visando o processamento industrial em Dourados, MS. Revista Raízes e Amidos Tropicais, Botucatu, v. 3, n. 1, out. 2007. Disponível em: <http:// www.cerat.unesp.br/revistarat/volume3/artigos/102\%20 Auro\%200tsubo.pdef $>$. Acesso em: 18 abr. 2008.

PEREIRA NETO, A.; OTSUBO, A. A.; MARTINS, C. S. Cultivares elites de mandioca industrial, colhida com um ciclo, em Glória de Dourados, MS. In: CONGRESSO NACIONAL DE INICIAÇÃO CIENTÍFICA, 1., 2001, São Paulo. Anais... São Paulo: SEMESP, 2001. v. 1, p. 29.

SAGRILO, E.; OTSUBO, A. A.; SILVA, A. S. Desempenho produtivo de genótipos de mandioca no Vale do Ivinhema, MS. Revista Raízes e Amidos Tropicais, Botucatu, v. 3, n. 1, out. 2007. Disponível em: $<$ http://www.cerat.unesp.br/revistarat/volume3/153\%20 Edvaldo\%20Sagrilo.pdf $>$. Acesso em: 18 abr. 2008.
SAGRILO, E.; VIDIGAL FILHO, P. S.; PEQUENO, M. G.; SCAPIM, C. A.; GONÇALVES-VIDIGAL, M. C.; MAIA, R. R.; KVITSCHAL, M. V. Efeito da época de colheita no crescimento vegetativo, na produtividade e na qualidade de raízes de três cultivares de mandioca. Bragantia, Campinas, v. 61, n. 2, p. 115-125, 2002.

VIDIGAL FILHO, P. S.; PEQUENO, M. G.; SCAPIM, C. A.; VIDIGAL, M. C. G.; MAIA, R. R.; SAGRILO, E.; SIMON, G. A.; LIMA, R. S. Avaliação de cultivares de mandioca na região noroeste do Paraná. Bragantia, Campinas, v. 59, n. 1, p. 69-75, 2000.

ZATARIN, M.; MAIOR, J. A. B.; VALLE, T. L.; DAINEZI, L. C.; OLIVEIRA, A.. Potencial agronômico de clones e variedades elites de mandioca nas condições de Campo Grande, MS. In: CONGRESSO BRASILEIRO DE MANDIOCA, 11., 2005, Campo Grande. Anais... Campo Grande: Embrapa Agropecuária Oeste, 2005. 